\title{
Microhabitat Segregation between Black-spotted Pond Frogs, Pelophylax nigromaculatus, and Gold-striped Pond Frogis, P. plancyi (Anura: Ranidae)
}

\author{
Amaël Borzée ${ }^{1}$, Jin-Long Ren², Jia-Tang Li², Jordy Groffen ${ }^{1}$, Yikweon Jang ${ }^{1}$, Yi Yang ${ }^{3}$, and Kevin R. Messenger ${ }^{3}$ \\ ${ }^{1}$ Division of EcoScience and Department of Life Sciences, Ewha Woman’s University, Seoul, 03760, Republic of Korea (amaelborzee@gmail.com) \\ ${ }^{2}$ Chengdu Institute of Biology, Chinese Academy of Sciences, Chengdu, 610041, People’s Republic of China \\ ${ }^{3}$ Department of Biology and the Environment, Nanjing Forestry University, Nanjing, People’s Republic of China (kevinrmessenger@gmail.com)
}

$\mathrm{M}$ any organisms optimize the exploitation of resources by segregating microhabitats (e.g., Begon et al. 2006). In calling anurans, species with diel or seasonal overlap in advertisement call production are distributed such that each species uses a distinct calling space. For instance, some species are distributed in concentric rings around bodies of water. This pattern has been described for several families and includes, for instance, South African frogs in the genus Hyperolius (Hyperoliidae), in which $H$. marmoratus calls from the centers of ponds and $H$. pickersgilli from the edges (Kruger and $\mathrm{Du}$ Preez 2016). Similar partitioning of spatial resources has been documented for treefrogs (Hylidae) in the genus Dryophytes (= Hyla; see Duellman et al. 2016) in North America and Korea. In North America, D. gratiosus is surrounded by $D$. cinereus (Gerhardt et al. 1980; Lamb and Avise 1986) and in
Korea, D. suweonensis (see Dufresnes et al. 2016; Borzée et al. 2018; Zhang et al. 2019 for discussions of the taxonomic status of the species) calls from the centers of rice paddies and is surrounded by D. japonicus (Borzée et al. 2016a, 2016b). Yang et al. (1988) described the same pattern for Pelophylax nigromaculatus (Ranidae), which calls from the center of a body of water surrounded by $P$. chosenicus. Herein, we test the hypothesis that the same pattern will apply for $P$. nigromaculatus and $P$. plancyi (Fig. 1).

We collected data on 13-14 May 2017 at eight localities in the vicinity of Nanjing, Jiangsu Province, People's Republic of China $\left(31.755727^{\circ} \mathrm{N}, 118.826565^{\circ} \mathrm{E}\right.$; $31.758664^{\circ} \mathrm{N}, 118.826282^{\circ} \mathrm{E} ; 31.754786^{\circ} \mathrm{N}, 118.841453^{\circ} \mathrm{E}$; $31.756933^{\circ} \mathrm{N}, 118.845318^{\circ} \mathrm{E} ; 31.757210^{\circ} \mathrm{N}, 118.842911^{\circ} \mathrm{E}$; $31.922499^{\circ} \mathrm{N}, 118.770076^{\circ} \mathrm{E} ; 31.922624^{\circ} \mathrm{N}, 118.772136^{\circ} \mathrm{E}$;
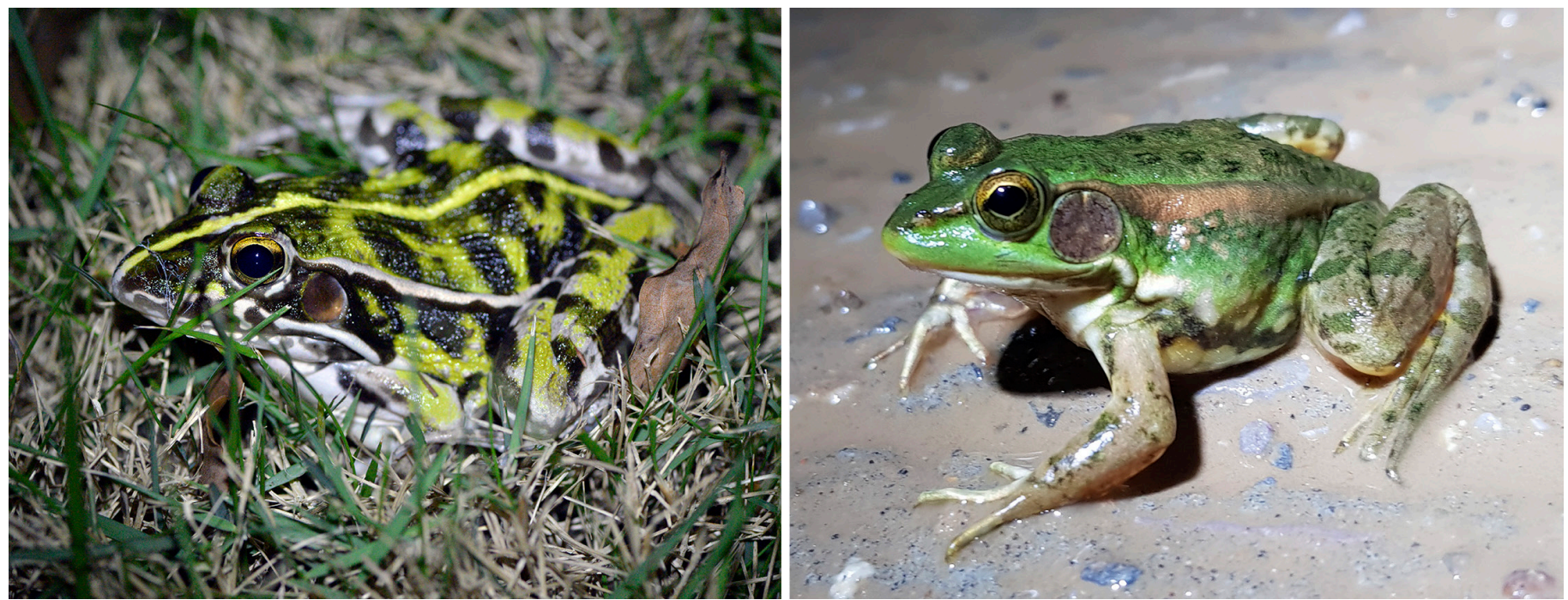

Fig. 1. Black-spotted Pond Frogs (Pelophylax nigromaculatus; left) and Gold-striped Pond Frogs (P. plancyi; right). Both individuals were photographed outside of their breeding habitat. Photographs by Amaël Borzée. 


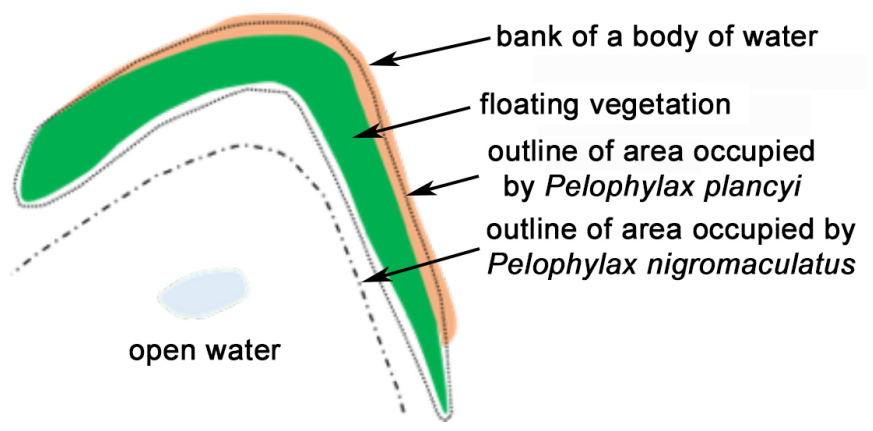

Fig. 2. Schematic representation of the spatial distribution of Blackspotted Pond Frogs (Pelophylax nigromaculatus) and Gold-striped Pond Frogs ( $P$. plancyi) around a body of water. Only one side of the body of water body is illustrated; note that calling male Gold-striped Pond Frogs completely surround the area used by Black-spotted Pond Frogs.

$\left.31.923374^{\circ} \mathrm{N}, 118.773635^{\circ} \mathrm{E}\right)$; on 4 July 2017 at two localities in Shanghai Municipality $\left(31.20858^{\circ} \mathrm{N}, 121.57875^{\circ} \mathrm{E}\right.$; $\left.31.33715^{\circ} \mathrm{N}, 121.50200^{\circ} \mathrm{E}\right)$; on 27 April 2018 in Jiaxing, Zhejiang Province $\left(30.715082^{\circ} \mathrm{N}, 120.768073^{\circ} \mathrm{E}\right)$; and on 28 April 2018 in Dafeng, Jiangsu Province $\left(33.481318^{\circ} \mathrm{N}\right.$, $120.503148^{\circ} \mathrm{E}$ ). Sites were at least $250 \mathrm{~m}$ apart from each other and involved the presence of at least one calling individual of each species. Observations at each site were thus considered geographically independent. The positions of calling individuals (both $P$. nigromaculatus and $P$. plancyi) were visually inspected and scored as within $3 \mathrm{~m}$ from the edge of the bodies of water or farther toward the center of the body of water. Only sections of the water bodies were inspected due to accessibility and all sites inspected had floating vegetation both within $3 \mathrm{~m}$ of the bank and toward the center. At all sites, $P$. plancyi was found close to the edges of the water, whereas $P$. nigromaculatus was found toward the center (Fig. $2)$. For the sites in Shanghai, the mean distance ( \pm one SD) between the bank and individual $P$. nigromaculatus was 3.56 $\pm 4.42 \mathrm{~m}(\mathrm{n}=10 ; 0.32-12.24 \mathrm{~m})$, whereas it was $1.6 \pm 1.63$ $\mathrm{m}(\mathrm{n}=5 ; 0-3.50 \mathrm{~m})$ for $P$. plancyi. All were from sites where floating vegetation allowed for this type of segregation.

These observations tentatively support our hypothesis of microhabitat segregation for calling sites between $P$. plancyi and $P$. nigromaculatus. An alternative explanation is that the evident segregation could be the result of habitat preference as the edges and centers of bodies of water usually supported different types of vegetation. Interestingly, the species did not always follow the pattern described above when only one of the two species was present. Also noteworthy is that such a pattern requires females of the internal ring species to cross the outer ring of males from the other species, which could explain the frequent instances of hybridization observed in species of Pelophylax (Liu et al. 2010)

\section{Acknowledgement}

This work was supported by a grant from the National Research Foundation of Korea (2017R1A2B2003579).

\section{Literature Cited}

Begon, M., C.R. Townsend, and J.L. Harper. 2006. Ecology: From Individuals to Ecosystems. 4th ed. Blackwell Publishing, Oxford, United Kingdom.

Borzée, A., J.Y. Kim, M.A.M. de Cunha, D. Lee, E. Sin, S. Oh, Y. Yi, and Y. Jang. 2016a. Temporal and spatial differentiation in microhabitat use: Implications for reproductive isolation and ecological niche specification. Integrative Zoology 11: 375-387.

Borzée, A., J.Y. Kim, and Y. Jang. 2016b. Asymmetric competition over calling sites in two closely related treefrog species. Scientific Reports 6: 32569.

Borzée, A., S. Kong, C. Didinger, H.Q. Nguyen, and Y. Jang. 2018. A ringspecies or a ring of species? Phylogenetic relationship between two treefrog species around the Yellow Sea: Dryophytes suweonensis and D. immaculatus. Herpetological Journal 28: 160-170.

Duellman, W.E., A.B. Marion, and S.B. Hedges. 2016. Phylogenetics, classification, and biogeography of the treefrogs (Amphibia: Anura: Arboranae). Zootaxa 4104: 1-109.

Dufresnes, C., S.N. Litvinchuk, A. Borzée, Y. Jang, J.-T. Li, I. Miura, N. Perrin, and M. Stöck. 2016. Phylogeography reveals an ancient cryptic radiation in East-Asian tree frogs (Hyla japonica group) and complex relationships between continental and island lineages. BMC Evolutionary Biology 16: 1-14.

Gerhardt, H.C., S.I. Guttman, and A.A. Karlin. 1980. Natural hybrids between Hyla cinerea and Hyla gratiosa: morphology, vocalization and electrophoretic analysis. Copeia: 577-584.

Kruger, D.J. and L.H. Du Preez. 2016. The effect of airplane noise on frogs: a case study on the Critically Endangered Pickersgill's reed frog (Hyperolius pickersgilli). Ecological Research 31: 393-405.

Lamb, T. and J.C. Avise. 1986. Directional introgression of mitochondrial DNA in a hybrid population of tree frogs-the influence of mating behavior. Proceedings of the National Academy of Science 83: 2526-2530.

Liu, K., F. Wang, W. Chen, L. Tu, M.-S. Min, K. Bi, and J. Fu. 2010. Rampant historical mitochondrial genome introgression between two species of green pond frogs, Pelophylax nigromaculatus and P. plancyi. BMC Evolutionary Biology 10: 201.

Yang, S., C. Yu, and B. Park. 1988. Natural hybridization and reproductive isolating mechanisms between two species of Rana nigromaculata and Rana plancyi (Anura). Korean Journal of Zoology 31: 1-10.

Zhang, J.-Y., B.E. Luu, D.-N. Yu, L.-P. Zhang, R. Al-attar, and K.B. Storey. 2019. The complete mitochondrial genome of Dryophytes versicolor: Phylogenetic relationship among Hylidae and mitochondrial protein-coding gene expression in response to freezing and anoxia. International Journal of Biological Macromolecules 132: 461-469. 